\title{
History of depression and risk of hyperemesis gravidarum: a population-based cohort study
}

\author{
Helena Kames Kjeldgaard ${ }^{1,2}$ • Malin Eberhard-Gran ${ }^{1,2,3}$ • Jūratė Šaltytė Benth ${ }^{1,2}$ • \\ Hedvig Nordeng ${ }^{3,4}$ • Åse Vigdis Vikanes ${ }^{5}$
}

Received: 21 December 2016 / Accepted: 26 December 2016 /Published online: 7 January 2017

(C) The Author(s) 2017. This article is published with open access at Springerlink.com

\begin{abstract}
Hyperemesis gravidarum (HG) is a pregnancy condition characterised by debilitating nausea and vomiting. HG has been associated with depression during pregnancy but the direction of the association remains unclear. The aim of this study was to assess whether previous depression is associated with HG. This is a population-based pregnancy cohort study using data from The Norwegian Mother and Child Cohort Study. The study reviewed 731 pregnancies with HG and 81,055 pregnancies without. Logistic regression analyses were performed to examine the association between a lifetime history of depression and hyperemesis gravidarum. Odds ratios were adjusted for symptoms of current depression, maternal age, parity, body mass index, smoking, sex of the child, education and pelvic girdle pain. A lifetime history of depression was associated with higher odds for hyperemesis gravidarum $(\mathrm{aOR}=1.49,95 \%$ CI $(1.23 ; 1.79))$. Two thirds of women with hyperemesis gravidarum had neither a history of depression nor symptoms of current depression, and $1.2 \%$ of women with a history of depression developed HG. A lifetime history of depression increased the risk of HG. However,
\end{abstract}

Helena Kames Kjeldgaard

Helena.Kames.Kjeldgaard@ahus.no

1 Health Services Research Unit, Akershus University Hospital, Post Box 1000, 1478 Lørenskog, Norway

2 Institute of Clinical Medicine, Campus Ahus, University of Oslo, Lørenskog, Norway

3 Domain for Mental and Physical Health, Norwegian Institute of Public Health, Oslo, Norway

4 PharmacoEpidemiology \& Drug Safety Research Group, Department of Pharmacy, School of Pharmacy, University of Oslo, Oslo, Norway

5 The Intervention Centre, Oslo University Hospital, Oslo, Norway given the fact that only $1.2 \%$ of women with a history of depression developed $\mathrm{HG}$ and that the majority of women with HG had no symptoms of depression, depression does not seem to be a main driver in the aetiology of HG.

Keywords Depression $\cdot$ Hyperemesis gravidarum $\cdot$ Mental health $\cdot$ Nausea and vomiting $\cdot$ Norwegian Mother and Child Cohort Study

\section{Introduction}

Nausea and vomiting in pregnancy (NVP) is common and affects up to $80 \%$ of all pregnancies (Gadsby et al. 1993). Unlike NVP, hyperemesis gravidarum (HG) is characterised by severe, debilitating symptoms. The International Classification of Diseases (ICD-10) describes HG as excessive vomiting starting before the 22 nd week of gestation with (severe HG) or without (mild HG) metabolic disturbances (World Health Organization 2004). Although estimated to affect 0.3 to $2 \%$ of all pregnancies (Eliakim et al. 2000), HG is a primary reason for sick leave (Dorheim et al. 2013) and hospitalisation during pregnancy (Gazmararian et al. 2002). The aetiology and the pathogenesis of HG are unclear, and it remains unknown whether NVP and HG are independent conditions or if $\mathrm{HG}$ represents the extreme of a continuum of NVP.

HG has historically been explained by a variety of psychological mechanisms that have been subjected to stigma (Fairweather 1968). Other hypotheses have been proposed, including genetic components (Corey et al. 1992; Fejzo et al. 2008), endocrine factors and Helicobacter pylori infection, but none of these have proven sufficient to explain HG (Verberg et al. 2005). Although, HG is today considered a disease of unclear pathophysiology (Grooten et al. 2015), 
clinical practice still includes evaluation of hyperemetic women for psychiatric disease (Kim et al. 2009). Women with HG report lack of support from their healthcare providers (Heitmann et al. 2016; Poursharif et al. 2008), which may have severe consequences such as termination of pregnancy and psychological sequelae (Poursharif et al. 2008; Poursharif et al. 2007).

HG has consistently been associated with mental distress such as depression and anxiety. Previous studies are, however, often small with a medium to high risk of bias (Mitchell-Jones et al. 2016) or have limited availability of co-variates (Fell et al. 2006; Seng et al. 2007). Prior research has mainly focused on the association between anxiety/depression and $\mathrm{HG}$ during pregnancy, whereas the effect of anxiety/depression prior to pregnancy remains to be elucidated. Furthermore, few studies have used reliable psychometric instruments to assess anxiety/depression before pregnancy, rendering causal inferences difficult (Fell et al. 2006; Seng et al. 2007). Thus, a key question remains of whether mental distress leads to $\mathrm{HG}$ or HG leads to mental distress.

The aim of the present study was to assess whether a lifetime history of depression is associated with HG. The Norwegian Mother and Child Cohort Study, comprising more than 100,000 pregnancies, provides a unique opportunity to explore this association.

\section{Materials and methods}

\section{Study design and study population}

From 1998 to 2008, all pregnant women scheduled to give birth at 50 of Norway's 52 hospitals with maternity units received a postal invitation to participate in The Norwegian Mother and Child Cohort Study (MoBa) together with appointments for routine ultrasound examination at around week 17 of pregnancy. All participants signed an informed consent form (Magnus et al. 2016; Magnus et al. 2006). MoBa was approved by the Regional Committee for Medical Research Ethics and by the Norwegian Data Protection Authority. The protocol for the current study was submitted to the Norwegian Institute of Public Health, who, upon approval, supplied the researchers of this study with anonymised data through contract (PDB 1527, www.fhi.no/moba).

The current study is based on version 8 of the quality-assured data files linked to the Medical Birth Registry of Norway (MBRN). The MBRN is based on the compulsory notification of every birth or late abortion in Norway from the 16th week of gestation, including information regarding pregnancy-related complications (Irgens 2000). Approximately $40 \%$ of the invited women participated, and each pregnancy was registered with a unique identification number (Magnus et al. 2006).
The analyses of the current study are based on two questionnaires distributed in pregnancy week 17 (Q1) and week 30 (Q2). Q1 covers background factors including previous pregnancies, medical history before and during pregnancy, medication; occupation, lifestyle habits and mental health. Q2 provides information about the mental and physical health at this stage of pregnancy as well as changes in work situation and habits. English translations of the questionnaires can be found at http://www.fhi.no/moba.

We included all singleton pregnancies $(n=112,288)$. We excluded women with missing information on history of depression $(n=3605)$, symptoms of depression at the 17 th gestational week, hospitalisation $(n=19,275)$, sex of the child $(n=207)$ and education $(n=15,707)$. Some women had missing values on more than one variable. The final sample comprised $81.786,72.8 \%$ of the total sample.

\section{Variables}

In accordance with previous studies on MoBa data (Vikanes et al. 2010, 2013), HG was defined as prolonged nausea and vomiting leading to hospitalisation before the 25 th gestational week as reported in Q2 (week 30). This definition was chosen in order to clearly separate HG from normal levels of NVP.

The main predictor was a lifetime history of depression, measured by the Kendler's lifetime major depression scale (KLTDS). The KLTDS was defined using five of the nine symptomatic criteria for major depression in DSM-III-R: Have you ever experienced the following for a continuous period of 2 weeks or more: (1) felt depressed, sad; (2) had problems with appetite or eaten too much; (3) been bothered by feeling weaker or a lack of energy; (4) really blamed yourself and felt worthless and (5) had problems with concentration or had problems making decisions. The response to each question was yes or no. A history of depression was defined as present if a minimum of three of the five symptoms and sad mood were reported to occur simultaneously for more than 2 weeks (Kendler et al. 1993).

A five-item short version (SCL-5) of the Hopkins Symptom Checklist-25 (SCL-25) was used as a proxy for current depression in pregnancy week 17 . The SCL-5 is highly correlated with the SCL-25 (correlation coefficient of 0.92) (Tambs and Moum 1993) and consists of the following questions: Have you been bothered by any of the following during the last 2 weeks: (1) feeling fearful, (2) nervousness or shakiness inside, (3) feeling hopeless about the future, (4) feeling blue and (5) worrying too much about things. The response categories ranged from 'not bothered' to 'very bothered' (range 1-4), with a maximum total score of 20. Symptoms of current depression were defined as a mean score $>2$ (Strand et al. 2003), which has been shown to provide the same prevalence estimate of a depressive disorder as the Composite International Diagnostic Interview (Robins et al. 
1988; Sandanger et al. 1998). Missing values in the dichotomised version of the SCL-5 were handled as follows. First, the average score on existing items was calculated for each case if at least three of five questions were answered. If the average of the existing items was clearly above or below the cut-off and could not be affected by imputation of missing values, it was dichotomised to zero or one, as appropriate. Imputation was not performed in cases where the average score was not uniquely defining the value above or below cut-off. Altogether, $N=18$ cases were imputed.

Co-variates and possible confounders obtained from the MBRN included sex of the child (Rashid et al. 2012), maternal age and parity. Co-variates and possible confounders obtained from MoBa Q1 were socio-economic status, BMI and smoking (Vikanes et al. 2010). Pelvic girdle pain was obtained from MoBa Q2 (Bjelland et al. 2013; Chortatos et al. 2015). Regarding parity, women were dichotomised as either primiparous or multiparous. Education was used as a proxy for socio-economic status, and length of education (in years) was divided into three categories. Pre-pregnancy body mass index (BMI) was calculated as weight/height ${ }^{2}$. Women shorter than $120 \mathrm{~cm}(n=199)$ and women weighing more than $150 \mathrm{~kg}$ or less than $40 \mathrm{~kg}$ were excluded $(n=58)$. Also, those reporting reduction in weight by more than $20 \mathrm{~kg}$ or increase in weight by more than $50 \mathrm{~kg}$ since the start of pregnancy were excluded $(n=65)$. Smoking was assessed as a yes/no response to the question 'did you smoke 3 months before pregnancy' (Vikanes et al. 2010). Pelvic girdle pain was defined as pain in the anterior pelvis and on both sides in the posterior pelvis (Bjelland et al. 2013).

Other co-variates including $H$. pylori infection (Li et al. 2015), gastrointestinal disorders, rheumatoid arthritis, preeclampsia, chronic hypertension, type 1 diabetes, asthma (Bolin et al. 2013; Fell et al. 2006; Jorgensen et al. 2012), eating disorders (Torgersen et al. 2008) and ethnicity (Vikanes et al. 2008) were considered but not included in the final analysis due to a small number of women with these disorders in the HG group. Thyroid disease was not included in the analysis as the questionnaire form does not allow differentiation between hypothyroid and hyperthyroid disease.

\section{Statistical analysis}

Demographic and clinical characteristics among women with and without $\mathrm{HG}$ and for the entire sample were presented as frequencies and percentages or means and standard deviations (SD).

To assess the association between a lifetime history of depression and HG, a logistic regression model was estimated. Due to multiple births, some women had several recordings in the data set. According to the intra-women correlation coefficient, there was some degree of clustering detected. Thus, the generalised estimating equations (GEE) model correctly adjusting the estimates for intra-women correlations was fitted.

A number of potential predictors and confounders were considered. In order to test our hypotheses, a data splitting approach was applied (Dahl et al. 2008). According to this approach, the data set was split into two random parts containing approximately 30\% (part I) and 70\% (part II) of observations. Splitting was performed within stratas defined by several key variables. Part I (pilot) was used to construct a model for HG. Only predictors significant at the $5 \%$ level or those otherwise considered important were left in the model estimated on pilot data. The hypothesis testing was then performed on part II (test) data. Only the results with $P$ values below 0.05 in the test data analyses were accepted as significant, regardless of significance level in the pilot part. Once the hypotheses were tested, the model was estimated on the entire data set to achieve most accurate estimates for the model parameters. Due to the numerous predictors considered, the level of significance was set to 0.005 when interpreting the results in the entire data set.

The interaction between BMI and smoking status was assessed and kept in the model if significant.

All analyses were performed by SPSS v 22.

\section{Results}

Characteristics for the $\mathrm{HG}$ group and comparison group are presented in Table 1. The mean age of pregnant women was 30.3 years ( $15-47$ years; SD 4.5 years) and $45 \%$ were primipara. A total of $731(0.9 \%)$ women reported hospital admission due to HG. More than $20 \%(17,351 / 81,786)$ of the women reported a lifetime history of depression, whereas $6.1 \%$ $(4981 / 81,786)$ reported symptoms of current depression at the 17 th gestational week.

In the binary logistic regression model, a lifetime history of depression was associated with higher odds for HG (unadjusted $\mathrm{OR}=1.53,95 \% \mathrm{CI}(1.29 ; 1.83))$. Adjusting for potential confounders including symptoms of depression in gestational week 17 did not influence our results (adjusted OR $=1.49$, $95 \%$ CI $(1.23 ; 1.79))$.

Symptoms of depression at the 17 th gestational week was independently associated with $\mathrm{HG}$ in the multivariate model $(\mathrm{OR}=1.71,95 \% \mathrm{CI}(1.31 ; 2.23))$. As shown on Table 2 , other factors positively associated with $\mathrm{HG}$ included short education, female sex of the child, multiparity, younger age of the mother and pelvic girdle pain. Pre-pregnancy BMI did not differ between women with and without $\mathrm{HG}$, and smoking was negatively associated with HG.

We also assessed whether women with a history of depression were more likely to be hospitalised during pregnancy in general. Among women with previous depression, $7.7 \%$ were hospitalised during pregnancy compared to $5.2 \%$ without; 
Table 1 Characteristics of the sample according to HG status among 81,786 women

\begin{tabular}{|c|c|c|c|}
\hline & HG $n(\%)$ & No HG $n(\%)$ & Total $n(\%)$ \\
\hline \multicolumn{4}{|l|}{ History of depression } \\
\hline No & $520(71.1)$ & $63,915(78.9)$ & $64,435(78.8)$ \\
\hline Yes & $211(28.9)$ & $17,140(21.1)$ & $17,351(21.2)$ \\
\hline \multicolumn{4}{|c|}{ Symptoms of current depression } \\
\hline Low score & $650(88.9)$ & $76,155(94.0)$ & 76,805 (93.9) \\
\hline High score & $81(11.1)$ & $4900(6.0)$ & $4981(6.1)$ \\
\hline \multicolumn{4}{|l|}{ Parity } \\
\hline Primipara & $287(39.3)$ & $36,480(45.0)$ & $36,767(45.0)$ \\
\hline Multipara & $444(60.7)$ & $44,575(55.0)$ & $45,019(55.0)$ \\
\hline \multicolumn{4}{|c|}{ Length of education (years) } \\
\hline$<12$ & $79(10.8)$ & $5599(6.9)$ & $5678(6.9)$ \\
\hline $13-16$ & $536(73.3)$ & $56,034(69.1)$ & $56,570(69.2)$ \\
\hline$>16$ & $116(15.9)$ & $19,422(24.0)$ & $19,538(23.9)$ \\
\hline \multicolumn{4}{|l|}{ Smoking } \\
\hline No & 495 (79.5) & $49,153(69.3)$ & $49,648(69.4)$ \\
\hline Yes & $128(20.5)$ & $21,811(30.7)$ & $21,939(30.6)$ \\
\hline \multicolumn{4}{|l|}{ Sex of the child } \\
\hline Boy & $307(42.0)$ & $41,571(51.3)$ & $41,878(51.2)$ \\
\hline Girl & $424(58.0)$ & $39,484(48.7)$ & $39,908(48.8)$ \\
\hline \multicolumn{4}{|l|}{ Pelvic girdle pain } \\
\hline No & $583(79.8)$ & $69,145(85.3)$ & $69,728(85.3)$ \\
\hline \multirow[t]{2}{*}{ Yes } & $148(20.2)$ & $11,910(14.7)$ & $12,058(14.7)$ \\
\hline & HG mean (SD) & No HG mean (SD) & Total mean (SD) \\
\hline Maternal age & $29.3(4.9)$ & $30.3(4.5)$ & $30.3(4.5)$ \\
\hline Pre-pregnancy BMI & $24.5(4.2)$ & $24.1(4.3)$ & $24.1(4.3)$ \\
\hline
\end{tabular}

history of depression was associated with higher odds for hospitalisation $(\mathrm{OR}=1.52,95 \% \mathrm{CI}(1.42 ; 1.62))$.

Although HG was positively associated with depression, the majority of women with $\mathrm{HG}(66 \%, 489 / 740)$ neither had a lifetime history of depression nor symptoms of depression in the 17th gestational week as shown in Fig. 1. Furthermore, only $1.2 \%$ of women with previous depression developed HG.

\section{Discussion}

The main finding of the present study was that having a lifetime history of depression was associated with $50 \%$ higher odds for HG. The majority of women with HG did not, however, have a history of depression, and less than $2 \%$ of women with previous depression developed HG.

The results are in line with previous research. Using health insurance data from the Midwestern USA between 2000 and 2004, Seng et al. (2007) found that a diagnosis of depression before pregnancy was positively associated with $\mathrm{HG}$ in a population of 11,016 women, including $208 \mathrm{HG}$ pregnancies $(\mathrm{OR}=3.2,95 \% \mathrm{CI}(2.0 ; 5.2))$. Additionally, they found that the burden of illness increased the likelihood of HG. Having had a psychiatric or somatic condition before pregnancy increased the odds for HG twofold, while having had both a psychiatric and somatic condition increased the odds fourfold. The study design permitted the identification of psychiatric diagnoses occurring before pregnancy, but information about other co-variates was limited.

Another large cohort study comprising 157,922 women, of whom 1301 had HG, was extracted from a population-based healthcare database covering all deliveries to residents of Nova Scotia, Canada, between 1988 and 2002 (Fell et al. 2006). The
Table 2 Unadjusted and adjusted odds ratios (OR) with $95 \%$ confidence intervals (CI) for hyperemesis gravidarum ( $n=611,0.9 \%$ ) among 69,864 pregnancies

\begin{tabular}{|c|c|c|c|c|}
\hline & $\begin{array}{l}\text { Unadjusted OR } \\
(95 \% \mathrm{CI})\end{array}$ & $P$ value & $\begin{array}{l}\text { Adjusted OR } \\
(95 \% \mathrm{CI})\end{array}$ & $P$ value \\
\hline \multicolumn{5}{|l|}{ History of depression } \\
\hline No & 1 & - & 1 & - \\
\hline Yes & $1.53(1.29 ; 1.83)$ & $<0.001$ & $1.49(1.23 ; 1.79)$ & $<0.001$ \\
\hline \multicolumn{5}{|c|}{ Symptoms of current depression } \\
\hline Low score & 1 & - & 1 & - \\
\hline High score & $2.11(1.65 ; 2.69)$ & $<0.001$ & $1.71(1.31 ; 2.23)$ & $<0.001$ \\
\hline Maternal age & $0.94(0.93 ; 0.96)$ & $<0.001$ & $0.93(0.91 ; 0.95)$ & $<0.001$ \\
\hline \multicolumn{5}{|l|}{ Parity } \\
\hline Primipara & 1 & - & 1 & - \\
\hline Multipara & $1.24(1.05 ; 1.45)$ & 0.010 & $1.43(1.20 ; 1.69)$ & $<0.001$ \\
\hline \multicolumn{5}{|c|}{ Length of education (years) } \\
\hline$<12$ & $2.42(1.76 ; 3.32)$ & $<0.001$ & $1.91(1.36 ; 2.69)$ & $<0.001$ \\
\hline $13-16$ & $1.64(1.31 ; 2.06)$ & $<0.001$ & $1.44(1.13 ; 1.82)$ & 0.003 \\
\hline$>16$ & 1 & - & 1 & - \\
\hline Pre-pregnancy BMI & $1.03(1.01 ; 1.04)$ & 0.002 & $1.02(1.00 ; 1.04)$ & 0.030 \\
\hline \multicolumn{5}{|l|}{ Smoking } \\
\hline No & 1 & - & 1 & - \\
\hline Yes & $0.60(0.49 ; 0.72)$ & $<0.001$ & $0.46(0.37 ; 0.56)$ & $<0.001$ \\
\hline \multicolumn{5}{|l|}{ Sex of the child } \\
\hline Boy & 1 & - & 1 & - \\
\hline Girl & $1.49(1.27 ; 1.75)$ & $<0.001$ & $1.50(1.28 ; 1.76)$ & $<0.001$ \\
\hline \multicolumn{5}{|l|}{ Pelvic girdle pain } \\
\hline No & 1 & - & 1 & - \\
\hline Yes & $1.52(1.25 ; 1.85)$ & $<0.001$ & $1.30(1.06 ; 1.59)$ & 0.011 \\
\hline
\end{tabular}


Fig. 1 The total number of women with $a \mathrm{HG}(n=731), b$ a history of depression $(\mathrm{n}=17,351)$ and $c$ symptoms of current depression $(\mathrm{n}=4981)$ among 81,786 women in the Norwegian Mother and Child Cohort Study. The number of women with $\mathrm{HG}$ and a history of depression ( $a b$, $n=211$ ); with $\mathrm{HG}$ and symptoms of current depression $(a c, n=81)$ and with HG, a history of depression and symptoms of current depression $(a b c, n=50)$. The number of women with no HG and a history of depression and symptoms of current depression $(b c, n=2910)$

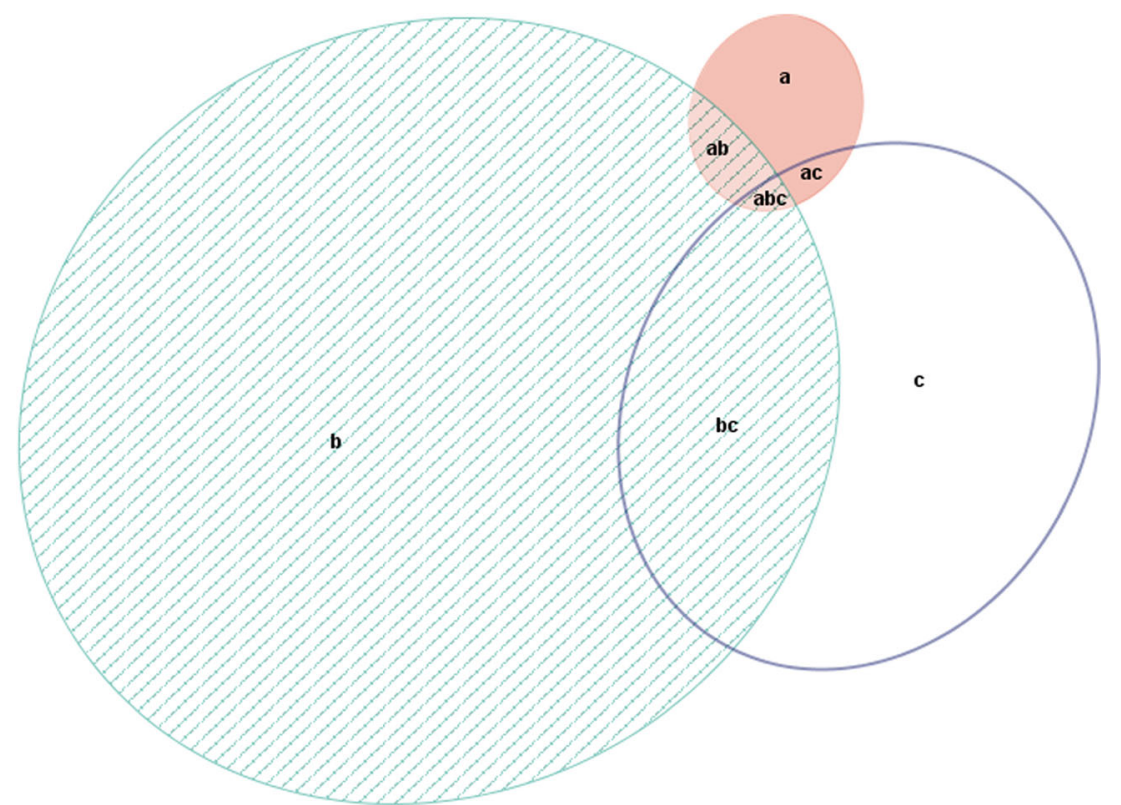

study revealed a fourfold higher risk of $\mathrm{HG}$ in women with psychiatric disease $(\mathrm{RR}=4.1,95 \% \mathrm{CI}(3.0 ; 5.7))$. The timing or types of psychiatric disease were not specified, but a crude RR of 2.5 with $95 \% \mathrm{CI}(1.5 ; 4.2)$ was reported for $\mathrm{HG}$ in women with depression compared to women without depression.

On the other hand, Magtira et al. (2014) found no statistically significant differences in the prevalence of psychiatric conditions prior to the first pregnancy when comparing 84 women with recurrence of HG with 34 women with no recurrence. The authors predicted that if psychiatric symptoms positively correlate with $\mathrm{HG}$, then psychiatric symptoms would correlate positively with recurrence risk. As the study was based on data from an online survey, the participating women were not randomly selected among women with HG and may therefore have had a different risk profile from the women who did not participate (Bornehag et al. 2012). Additionally, only women who had had at least two pregnancies lasting beyond the second trimester were included, which may introduce recall bias, e.g. whether psychiatric symptoms preceded pregnancy, or selection bias as women with poor psychosocial health may have been less likely to continue participation, as were women terminating their pregnancies due to $\mathrm{HG}$ (McDonald et al. 2013).

Given the nature of the MoBa data, we were able to explore whether symptoms of depression in the current pregnancy were independently associated with HG. Consistent with a recent meta-analysis (Mitchell-Jones et al. 2016), we found an association between $\mathrm{HG}$ and depression during pregnancy. Two prospective studies, both excluding women with a history of psychiatric disease, also reported that women with $\mathrm{HG}$ were more likely to suffer from symptoms of anxiety and depression during pregnancy compared to asymptomatic pregnant women (Aksoy et al. 2015; Pirimoglu et al. 2010).
It was therefore argued that psychological distress was a consequence of $\mathrm{HG}$ rather than the cause (Aksoy et al. 2015).

Since hospitalisation due to prolonged NVP was a requirement for having HG in the current study, our results may have been biased by a greater likelihood of being hospitalised among women with a history of depression (Atanackovic et al. 2001). A relationship between depression and severity of NVP has previously been suggested (Kelly et al. 2001; Mazzotta et al. 2000) although other studies do not support this finding (Swallow et al. 2004; Tan et al. 2010). We therefore assessed whether women with previous depression were more likely to be hospitalised in general during pregnancy. Previous depression was associated with hospitalisation $(\mathrm{OR}=1.52,95 \% \mathrm{CI}(1.42 ; 1.62))$, which may have contributed to overestimating the effect of previous depression on the risk of HG. However, in Norway, only women with severe symptoms of $\mathrm{HG}$, including metabolic disturbances, are hospitalised. Additionally, there is no tradition for outpatient treatment for these patients. This indicates that our sample is restricted to severe $\mathrm{HG}$ cases corresponding to ICD 10 code $\mathrm{O} 21.1$, and it is therefore unlikely that the women have been hospitalised due to depression. Given that hospital care in Norway is free of charge, it is furthermore unlikely that more socially disadvantaged women are less likely to be hospitalised.

Several studies show that a variety of somatic diseases such as pelvic girdle pain, $H$. pylori infection, thyroid disease, gastrointestinal disorders, rheumatoid arthritis, pre-eclampsia, chronic hypertension, type 1 diabetes, asthma and eating disorders are associated with higher risk of HG (Bolin et al. 2013; Fell et al. 2006; Jorgensen et al. 2012; Li et al. 2015; Seng et al. 2007; Torgersen et al. 2008). However, in the present study, the number of $\mathrm{HG}$ cases with these conditions was too small to 
explore possible influences of these conditions. Our results should be interpreted with these limitations in mind.

HG is a diagnosis by exclusion and an international consensus on the definition of HG is yet to be established, limiting comparison of previous research (Mitchell-Jones et al. 2016). The lack of consensus is a challenge for clinicians who may need to distinguish milder forms of HG from more common nausea and vomiting in pregnancy (Grooten et al. 2015). Inadequate care of women with HG may have severe consequences including therapeutic abortions, Wernicke's encephalopathy and even death (Eliakim et al. 2000; Poursharif et al. 2007). Adverse pregnancy outcomes such as low birth weight and preterm delivery may in particular affect HG women with poor pregnancy weight gain $(<7 \mathrm{~kg})$ (Dodds et al. 2006). Adequate care of women with $\mathrm{HG}$ is thus of the utmost importance.

To our knowledge, this is the first time a large, high-quality data set enables the study of the associations between a history of depression and HG and symptoms of depression during pregnancy and HG. Our results advocate that routine psychiatric consultations of HG women may be unnecessary. Treatment should focus on relief of somatic complaints and ensure the health of the mother and child.

The large number of HG pregnancies is a major strength of the current study. Furthermore, the study covered all regions of Norway, and the prospective nature of data collection minimises the risk of recall bias. To date, more than 400 articles have been published based on MoBa data. Around $40 \%$ of the invited women participated in the study, introducing a possibility of self-selection bias. However, a recent study looking into potential bias by skewed selection of participants in MoBa found that the participant selection influenced the prevalence estimates but not the exposure outcome associations (Nilsen et al. 2009). Women known to be underrepresented in MoBa include single women, those with shorter education, those under 25 years of age, immigrants and smokers (Nilsen et al. 2009; Vikanes et al. 2010). Hospitalisation for HG was assessed retrospectively; however, recall bias is highly unlikely due to the relatively short interval between hospitalisation and reporting of HG in week 32 of pregnancy (Vikanes et al. 2010). The comparison group comprised all other pregnant women in the study, including those with complications other than HG, reducing the risk of overestimating the association between previous depression and HG.

The KLTDS and SCL-5 are the only available measures of mental health in the MoBa study. Unlike clinical interviews, the KLTDS and SCL-5 cannot be used to diagnose depression. The scales have, however, been developed and validated to measure symptoms of depression in population studies. Extensive questionnaire studies with a broad scope such as the MoBa study often have a shortage of space for the original lengthy psychometric instruments, and short versions may be useful to improve response rates. While the short versions affect the measurement precision, the precision remains sufficient for epidemiological purposes (Strand et al. 2003; Tambs and Moum 1993; Tambs and Røysamb 2014).

The fact that a history of depression was not measured before pregnancy is a limitation of our study. Women responded to the KLTDS in gestational week 17, which for most women with $\mathrm{HG}$ is after the onset of severe nausea and vomiting. This may have affected their response. In our analyses, we therefore adjusted for symptoms of current depression at the 17th gestational week to quantify the direct effect of a previous depression on HG. The effect estimates changed only slightly in the adjusted model indicating that KLTDS and SCL-5 cover different aspects of women's mental health in relation to HG.

\section{Conclusion}

In conclusion, a lifetime history of depression increased the odds for hospitalisation for HG by approximately $50 \%$. However, two thirds of women with HG had neither a history of depression nor symptoms of depression at the 17th gestational week. Given the fact that only $1.2 \%$ of women with previous depression developed HG, depression does not appear to be a main driver in the aetiology and pathogenesis of HG. Our results advocate that routine psychiatric consultations may be unnecessary.

Acknowledgements We are grateful to all of the women and their families for participating in this continuing cohort study.

\section{Compliance with ethical standards}

Conflict of interest The authors declare that they have no conflict of interest.

Funding The Norwegian Mother and Child Cohort Study is supported by the Norwegian Ministry of Health and the Ministry of Education and Research, NIH/NIEHS (contract no. N01-ES-75558), NIH/NINDS (grant no. 1 UO1 NS 047537-01 and grant no. 2 UO1 NS 047537-06A1). The present study was supported by the South-Eastern Norway Regional Health Authority (grant no. 2014003). The funding sources had no role in the conduct of the study.

Open Access This article is distributed under the terms of the Creative Commons Attribution 4.0 International License (http:// creativecommons.org/licenses/by/4.0/), which permits unrestricted use, distribution, and reproduction in any medium, provided you give appropriate credit to the original author(s) and the source, provide a link to the Creative Commons license, and indicate if changes were made. 


\section{References}

Aksoy H, Aksoy U, Karadag OI, Hacimusalar Y, Acmaz G, Aykut G, Cagli F, Yucel B, Aydin T, Babayigit MA (2015) Depression levels in patients with hyperemesis gravidarum: a prospective case-control study. SpringerPlus 4:34. doi:10.1186/s40064-015-0820-2

Atanackovic G, Wolpin J, Koren G (2001) Determinants of the need for hospital care among women with nausea and vomiting of pregnancy. Clin Invest Med 24:90-93

Bjelland EK, Stuge B, Engdahl B, Eberhard-Gran M (2013) The effect of emotional distress on persistent pelvic girdle pain after delivery: a longitudinal population study. BJOG 120:32-40. doi:10.1111/14710528.12029

Bolin M, Akerud H, Cnattingius S, Stephansson O, Wikstrom AK (2013) Hyperemesis gravidarum and risks of placental dysfunction disorders: a population-based cohort study. BJOG 120:541-547. doi:10.1111/1471-0528.12132

Bornehag CG, Moniruzzaman S, Larsson M, Lindstrom CB, Hasselgren M, Bodin A, von Kobyletzkic LB, Carlstedt F, Lundin F, Nanberg E, Jonsson BA, Sigsgaard T, Janson S (2012) The SELMA study: a birth cohort study in Sweden following more than 2000 motherchild pairs. Paediatr Perinat Epidemiol 26:456-467. doi:10.1111 j.1365-3016.2012.01314.x

Chortatos A, Haugen M, Iversen PO, Vikanes A, Eberhard-Gran M, Bjelland EK, Magnus P, Veierod MB (2015) Pregnancy complications and birth outcomes among women experiencing nausea only or nausea and vomiting during pregnancy in the Norwegian Mother and Child Cohort Study. BMC Pregnancy Childbirth 15:138. doi:10.1186/s12884-015-0580-6

Corey LA, Berg K, Solaas MH, Nance WE (1992) The epidemiology of pregnancy complications and outcome in a Norwegian twin population. Obstet Gynecol 80:989-994

Dahl FA, Grotle M, Saltyte Benth J, Natvig B (2008) Data splitting as a countermeasure against hypothesis fishing: with a case study of predictors for low back pain. Eur J Epidemiol 23:237-242. doi:10.1007/s10654-008-9230-x

Dodds L, Fell DB, Joseph KS, Allen VM, Butler B (2006) Outcomes of pregnancies complicated by hyperemesis gravidarum. Obstet Gynecol 107:285-292. doi:10.1097/01.AOG.0000195060.22832.cd

Dorheim SK, Bjorvatn B, Eberhard-Gran M (2013) Sick leave during pregnancy: a longitudinal study of rates and risk factors in a Norwegian population. BJOG 120:521-530. doi:10.1111/14710528.12035

Eliakim R, Abulafia O, Sherer DM (2000) Hyperemesis gravidarum: a current review. Am J Perinatol 17:207-218. doi:10.1055/s-20009424

Fairweather DV (1968) Nausea and vomiting in pregnancy. Am J Obstet Gynecol 102:135-175

Fejzo MS, Ingles SA, Wilson M, Wang W, MacGibbon K, Romero R, Goodwin TM (2008) High prevalence of severe nausea and vomiting of pregnancy and hyperemesis gravidarum among relatives of affected individuals. Eur J Obstet Gynecol Reprod Biol 141:13-17. doi:10.1016/j.ejogrb.2008.07.003

Fell DB, Dodds L, Joseph KS, Allen VM, Butler B (2006) Risk factors for hyperemesis gravidarum requiring hospital admission during pregnancy. Obstet Gynecol 107:277-284. doi:10.1097/01. aog.0000195059.82029.74

Gadsby R, Barnie-Adshead AM, Jagger C (1993) A prospective study of nausea and vomiting during pregnancy. Br J Gen Pract 43:245-248

Gazmararian JA, Petersen R, Jamieson DJ, Schild L, Adams MM, Deshpande AD, Franks AL (2002) Hospitalizations during pregnancy among managed care enrolees. Obstet Gynecol 100:94-100
Grooten IJ, Roseboom TJ, Painter RC (2015) Barriers and challenges in hyperemesis gravidarum research. Nutrition and metabolic insights 8:33-39. doi:10.4137/nmi.s29523

Heitmann K, Solheimsnes A, Havnen GC, Nordeng H, Holst L (2016) Treatment of nausea and vomiting during pregnancy - a crosssectional study among 712 Norwegian women. Eur J Clin Pharmacol. doi:10.1007/s00228-016-2012-6

Irgens LM (2000) The Medical Birth Registry of Norway. Epidemiological research and surveillance throughout 30 years. Acta Obstet Gynecol Scand 79:435-439

Jorgensen KT, Nielsen NM, Pedersen BV, Jacobsen S, Frisch M (2012) Hyperemesis, gestational hypertensive disorders, pregnancy losses and risk of autoimmune diseases in a Danish population-based cohort. J Autoimmun 38:J120-J128. doi:10.1016/j.jaut.2011.10.002

Kelly RH, Russo J, Katon W (2001) Somatic complaints among pregnant women cared for in obstetrics: normal pregnancy or depressive and anxiety symptom amplification revisited? Gen Hosp Psychiatry 23: $107-113$

Kendler KS, Neale MC, Kessler RC, Heath AC, Eaves LJ (1993) The lifetime history of major depression in women. Reliability of diagnosis and heritability. Arch Gen Psychiatry 50:863-870

Kim DR, Connolly KR, Cristancho P, Zappone M, Weinrieb RM (2009) Psychiatric consultation of patients with hyperemesis gravidarum. Arch Womens Ment Health 12:61-67. doi:10.1007/s00737-0090064-7

Li L, Li L, Zhou X, Xiao S, Gu H, Zhang G (2015) Helicobacter pylori infection is associated with an increased risk of hyperemesis gravidarum: a meta-analysis. Gastroenterol Res Pract 2015: 278905. doi: $10.1155 / 2015 / 278905$

Magnus P, Irgens LM, Haug K, Nystad W, Skjaerven R, Stoltenberg C (2006) Cohort profile: the Norwegian Mother and Child Cohort Study (MoBa). Int J Epidemiol 35:1146-1150. doi:10.1093 /ije/dyl170

Magnus P, Birke C, Vejrup K, Haugan A, Alsaker E, Daltveit AK, Handal M, Haugen M, Hoiseth G, Knudsen GP, Paltiel L, Schreuder P, Tambs K, Vold L, Stoltenberg C (2016) Cohort profile update: the Norwegian Mother and Child Cohort Study (MoBa). Int J Epidemiol 45:382-388. doi:10.1093/ije/dyw029

Magtira A, Paik Schoenberg F, MacGibbon K, Tabsh K, Fejzo MS (2014) Psychiatric factors do not affect recurrence risk of hyperemesis gravidarum. J Obstet Gynaecol Res. doi:10.1111/jog.12592

Mazzotta P, Stewart D, Atanackovic G, Koren G, Magee LA (2000) Psychosocial morbidity among women with nausea and vomiting of pregnancy: prevalence and association with anti-emetic therapy. J Psychosom Obstet Gynaecol 21:129-136

McDonald SW, Lyon AW, Benzies KM, McNeil DA, Lye SJ, Dolan SM, Pennell CE, Bocking AD, Tough SC (2013) The All Our Babies pregnancy cohort: design, methods, and participant characteristics. BMC Pregnancy Childbirth 13(Suppl 1):S2. doi:10.1186/14712393-13-s1-s2

Mitchell-Jones N, Gallos I, Farren J, Tobias A, Bottomley C, Bourne T (2016) Psychological morbidity associated with hyperemesis gravidarum; a systematic review and meta-analysis. BJOG doi. doi:10.1111/1471-0528.14180

Nilsen RM, Vollset SE, Gjessing HK, Skjaerven R, Melve KK, Schreuder P, Alsaker ER, Haug K, Daltveit AK, Magnus P (2009) Selfselection and bias in a large prospective pregnancy cohort in Norway. Paediatr Perinat Epidemiol 23:597-608. doi:10.1111 /j.1365-3016.2009.01062.x

Pirimoglu ZM, Guzelmeric K, Alpay B, Balcik O, Unal O, Turan MC (2010) Psychological factors of hyperemesis gravidarum by using the SCL-90-R questionnaire. Clin Exp Obstet Gynecol 37:56-59

Poursharif B, Korst LM, Macgibbon KW, Fejzo MS, Romero R, Goodwin TM (2007) Elective pregnancy termination in a large 
cohort of women with hyperemesis gravidarum. Contraception 76: 451-455. doi:10.1016/j.contraception.2007.08.009

Poursharif B, Korst LM, Fejzo MS, MacGibbon KW, Romero R, Goodwin TM (2008) The psychosocial burden of hyperemesis gravidarum. J Perinatol 28:176-181. doi:10.1038/sj.jp.7211906

Rashid M, Rashid MH, Malik F, Herath RP (2012) Hyperemesis gravidarum and fetal gender: a retrospective study. J Obstet Gynaecol 32:475-478. doi:10.3109/01443615.2012.666580

Robins LN, Wing J, Wittchen HU, Helzer JE, Babor TF, Burke J, Farmer A, Jablenski A, Pickens R, Regier DA et al (1988) The Composite International Diagnostic Interview. An epidemiologic instrument suitable for use in conjunction with different diagnostic systems and in different cultures. Arch Gen Psychiatry 45:1069-1077

Sandanger I, Moum T, Ingebrigtsen G, Dalgard OS, Sorensen T, Bruusgaard D (1998) Concordance between symptom screening and diagnostic procedure: the Hopkins Symptom Checklist-25 and the Composite International Diagnostic Interview I. Soc Psychiatry Psychiatr Epidemiol 33:345-354

Seng JS, Schrot JA, van De Ven C, Liberzon I (2007) Service use data analysis of pre-pregnancy psychiatric and somatic diagnoses in women with hyperemesis gravidarum. J Psychosom Obstet Gynaecol 28:209-217. doi:10.1080/01674820701262044

Strand BH, Dalgard OS, Tambs K, Rognerud M (2003) Measuring the mental health status of the Norwegian population: a comparison of the instruments SCL-25, SCL-10, SCL-5 and MHI-5 (SF-36). Nord J Psychiatry 57:113-118. doi:10.1080/08039480310000932

Swallow BL, Lindow SW, Masson EA, Hay DM (2004) Psychological health in early pregnancy: relationship with nausea and vomiting. J Obstet Gynaecol 24:28-32. doi:10.1080/01443610310001620251

Tambs K, Moum T (1993) How well can a few questionnaire items indicate anxiety and depression? Acta Psychiatr Scand 87:364-367
Tambs K, Røysamb E (2014) Selection of questions to short-form versions of original psychometric instruments in MoBa. Norsk epidemiologi 24:195-201

Tan PC, Vani S, Lim BK, Omar SZ (2010) Anxiety and depression in hyperemesis gravidarum: prevalence, risk factors and correlation with clinical severity. Eur J Obstet Gynecol Reprod Biol 149:153158. doi:10.1016/j.ejogrb.2009.12.031

Torgersen L, Von Holle A, Reichborn-Kjennerud T, Berg CK, Hamer R, Sullivan P, Bulik CM (2008) Nausea and vomiting of pregnancy in women with bulimia nervosa and eating disorders not otherwise specified. Int J Eat Disord 41:722-727. doi:10.1002/eat.20564

Verberg MF, Gillott DJ, Al-Fardan N, Grudzinskas JG (2005) Hyperemesis gravidarum, a literature review. Hum Reprod Update 11:527-539. doi:10.1093/humupd/dmi021

Vikanes A, Grjibovski AM, Vangen S, Magnus P (2008) Variations in prevalence of hyperemesis gravidarum by country of birth: a study of 900,074 pregnancies in Norway, 1967-2005. Scand J Public Health 36:135-142. doi:10.1177/1403494807085189

Vikanes A, Grjibovski AM, Vangen S, Gunnes N, Samuelsen SO, Magnus P (2010) Maternal body composition, smoking, and hyperemesis gravidarum. Ann Epidemiol 20:592-598. doi:10.1016/j.annepidem.2010.05.009

Vikanes AV, Stoer NC, Magnus P, Grjibovski AM (2013) Hyperemesis gravidarum and pregnancy outcomes in the Norwegian Mother and Child Cohort - a cohort study. BMC Pregnancy Childbirth 13:169. doi:10.1186/1471-2393-13-169

World Health Organization (2004) ICD-10, Chapter XV, Pregnancy, childbirth and the puerperium (O00-O99), Other maternal disorders predominantly related to pregnancy $(\mathrm{O} 20-\mathrm{O} 29)$. World Health Organization. http://apps.who.int/classifications/apps/icd/icd10 online2004/fr-icd.htm?go20.htm+ 